\title{
sciendo
}

\section{INFLUENCE OF BARN CLIMATE, BODY POSTURES AND MILK YIELD ON THE RESPIRATION RATE OF DAIRY COWS*}

\author{
Severino Pinto ${ }^{1,2}$, Gundula Hoffmann ${ }^{1 *}$, Christian Ammon ${ }^{1}$, Barbara Amon ${ }^{1,3}$, Wolfgang Heuwieser ${ }^{4}$, \\ Ilan Halachmi ${ }^{5}$, Thomas Banhazi ${ }^{6}$, Thomas Amon ${ }^{1,2}$
}

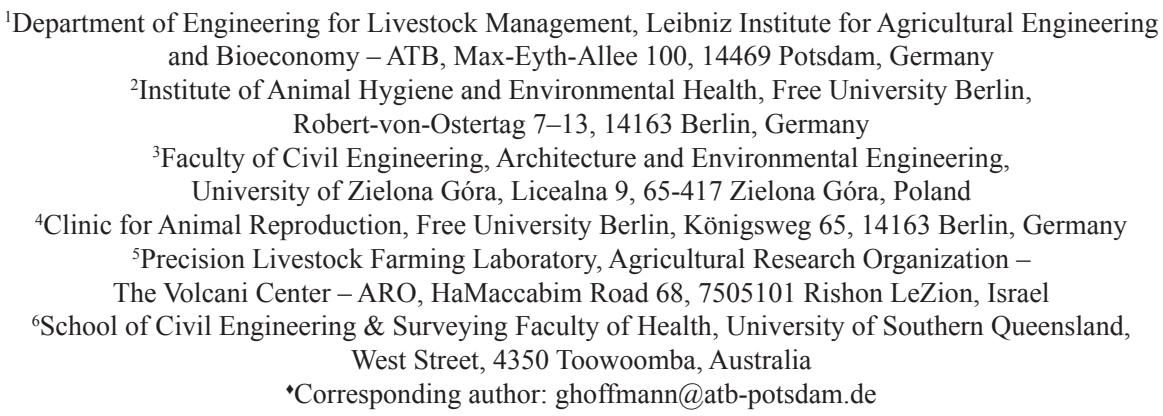

\begin{abstract}
The main objective of this study was to identify the influences of different climatic conditions and cow-related factors on the respiration rate (RR) of lactating dairy cows. Measurements were performed on 84 lactating Holstein Friesian dairy cows (first to eighth lactation) in Brandenburg, Germany. The RR was measured hourly or twice a day with up to three randomly chosen measurement days per week between $0700 \mathrm{~h}$ and $1500 \mathrm{~h}(\mathrm{GMT}+0100 \mathrm{~h})$ by counting right thoracoabdominal movements of the cows. Simultaneously with RR measurements, cow body postures (standing vs. lying) were documented. Cows' milk yield and days in milk were recorded daily. The ambient temperature and relative humidity of the barn were recorded every $5 \mathrm{~min}$ to calculate the current temperature-humidity index (THI). The data were analyzed for interactions between THI and cow-related factors (body postures and daily milk yield) on RR using a repeated measurement linear mixed model. There was a significant effect of the interaction between current THI category and body postures on RR. The RRs of cows in lying posture in the THI $<68,68 \leq \mathrm{THI}<72$ and $72 \leq$ THI $<80$ categories $(37,46$ and 53 breaths per minute $(\mathrm{bpm})$, respectively) were greater than those of standing cows in the same THI categories (30, 38 and $45 \mathrm{bpm}$, respectively). For each additional kilogram of milk produced daily, an increase of $0.23 \pm 0.19 \mathrm{bpm}$ in $R R$ was observed. Including cow-related factors may help to prevent uncertainties of $R R$ in heat stress predictions. In practical application, these factors should be included when predicting RR to evaluate heat stress on dairy farms.
\end{abstract}

Key words: dairy cow, heat stress, temperature-humidity index, cow-related factors, naturally ventilated barn

*Work financed from: OptiBarn project of the FACCE ERA-NET Plus Initiative Climate Smart Agriculture and Scholarship from the Coordination for Improvement of Higher Education Personnel CAPES (Brazil). 
Barn climate conditions are major contributors to animal stress in warm and temperate climate zones (Legates et al., 1991). Heat stress in cows occurs when the capacity for heat dissipation exceeds the range specified for normal activity and induces body adjustments to avoid physiological dysfunction (Kadzere et al., 2002). Therefore, heat stress in dairy cattle is considered as an important cause for reduced production and animal welfare (West, 2003; Herbut et al., 2015). A combination of ambient temperature and relative humidity as in the THI (temperature-humidity index) formula is commonly used to estimate the effects of barn climate conditions on heat load of cows (Heinicke et al., 2018; Herbut and Angrecka, 2018 a). The heat stress threshold for dairy cows varies with a THI between 68 and 72 (Armstrong, 1994; Bryant et al., 2007; Zimbelman and Collier, 2011). In order to ensure homeostasis and facilitate the release of excess metabolic heat into the environment, cattle adjust their behavior and physiological reactions (Berman, 2005; Soriani et al., 2013). Heat stress can be evidenced by its effects on the performance of dairy cows, but these signs only become apparent late after the onset of heat stress (Moallem et al., 2010; Schueller et al., 2014). In contrast, the physiological parameter respiration rate $(R R)$ has been shown to be a reliable and early indicator of heat stress in dairy cows (Kabuga, 1992; Gaughan et al., 2000; Chen et al., 2015). In addition, measuring RR has the advantage of being a non-invasive method that can determine stress in dairy cows without causing additional disturbance to the animals (Aharoni et al., 2005).

The RR of dairy cattle under thermo-neutral conditions ranges from 15 to 36 breaths per minute (bpm) (Rosenberger, 1990; Jackson and Cockcroft, 2008) and is influenced by THI and cow-related factors as body postures and milk yield (Kadzere et al., 2002; Berman, 2003). In a previous study of eight lactating Holstein dairy cows, the average observed RR was $60 \mathrm{bpm}$ under THI $=69.3 \pm 0.5$ and $87 \mathrm{bpm}$ during exposure to heat stress $(\mathrm{THI}=74.1 \pm 0.3)$ (Ominski et al., 2002). In addition to THI, various factors can influence the susceptibility of dairy cows to heat stress, such as sex, breed, body postures, lactation phase and milk production as well as shading and lack of shade (Gaughan et al., 2000; Berman, 2005). Despite being performed under similar THI range of 69 to 72, several studies of dairy cows have reported very different RR data, for example, 38.6 \pm 1.54 (mean \pm SEM) bpm in Costa et al. (2015 a), $50 \pm 2.4$ (mean \pm SEM) bpm in Kendall et al. (2007), and $88 \pm 16.5$ (mean \pm SD) bpm in Chen et al. (2015). Although studies of heat stress in dairy cows have demonstrated the impact of heat load on RR, body postures and milk yield have been considered as potential influential variables in previous data analyses.

Body posture is important as recumbent animals may show heat stress at lower temperatures than do standing animals (Berman, 2005; Herbut and Angrecka, 2018 b), and cows prefer to ruminate in a lying posture (Acatincăi et al., 2010). In addition, high yielding cows have a higher risk to suffer from heat stress in elevated temperatures (Kadzere et al., 2002; Gauly et al., 2013).

Based on current knowledge (Gaughan et al., 2000; Kadzere et al., 2002; Berman, 2005), the precise assessment of heat stress in dairy cows under varying THI requires the inclusion of cow-related factors such as body postures and milk yield into the assessment. In our study, we tested the hypotheses that: cows under high THI 
conditions show higher RRs; lying cows show higher RRs than standing cows; and cows with higher milk yields have higher RRs under different THI. Therefore, the objective of the present study was to evaluate the effects of barn climate conditions and cow-related factors, specifically, body postures (i.e., standing or lying) and daily milk yield, on the RR of lactating dairy cows.

\section{Material and methods}

\section{Animals, housing and management}

The study was conducted on the research dairy farm of the Agricultural Research and Education Center for Animal Breeding and Husbandry "Gross Kreutz" in Brandenburg, Germany (coordinates: 52 ${ }^{\circ} 23^{\prime} 47.4^{\prime \prime} \mathrm{N}, 12^{\circ} 46^{\prime} 02.8^{\prime \prime} \mathrm{E}$ ). The climate of this region is continental.

The data were collected during two time periods from June to August 2015 (hot period) and from January to April 2016 (cold period). The measurement days were chosen randomly based on expected weather conditions to cover a wide range of different situations. The experimental barn was designed for a capacity of 51 cows. The experimental animals were all lactating Holstein Friesian dairy cows from the first to eighth lactation. The group was a high-yielding group, and cows that dropped below $30 \mathrm{~kg}$ milk per day usually left the group within a few days. During the experimental period, the health status of the cows was constantly evaluated by a veterinarian who selected only healthy cows for the measurements. The cows were milked 3 times a day by an automatic milking system (AMS, Lely Astronaut A4, Maassluis, the Netherlands). The average daily milk yield was $41.08 \pm 6.72 \mathrm{~kg}$ per cow and the minimum yield observed in this high-yielding group was $25 \mathrm{~kg}$ per cow. The days in milk (DIM) ranged from 7 to 337 (mean \pm SD: $118.3 \pm 67.1$ ) during the study. Once a week, the body condition score (BCS) of the cows in the experiment was assessed, and the mode of the scores was 2.75 on a 1 to 5 point scale with 0.25 increments.

The cows were fed a totally mixed ration twice a day. Additional concentrate was fed in the AMS based on individual DIM and milk yield. The animals were housed in a naturally ventilated barn, as already used by Heinicke et al. (2018) and by Hempel et al. (2018), aligned in an NE-SW orientation with a floor area of $686 \mathrm{~m}^{2}\left(13.7 \mathrm{~m}^{2}\right.$ per cow). The feeding alley was $27.7 \mathrm{~m}$ long (animal feeding place ratio of $1: 1$ ). The cows had access to 51 lying cubicles with a mixture of straw and lime as bedding material, 34 of which were arranged in a double row and 17 in a single row. An automatic scraper removed manure from the concrete walking alleys approximately once per hour. The waiting area in front of the AMS had a slatted floor.

\section{Animal measurements}

The RR was observed visually by counting right thoracoabdominal movements for thirty seconds and multiplying the value by two (i.e., breaths per minute, bpm) at a distance of approximately $15 \mathrm{~m}$ between the animal and the observer, which is a method adapted from Kabuga (1992). In a pilot test, three was determined as 
the appropriate number of observers to reduce the variation in RR measurements between observers, so three observers were used for RR measurements during the experimental period. In the pilot test, the maximum difference found between two observers was $6 \mathrm{bpm}$, and the average relative difference between observers based on this maximum was $25.4 \%$ (95\% confidence limits: 21.2 to $30.2 \%$ ) or approximately $1.5 \mathrm{bpm}$ as an absolute value.

Two RR datasets were collected. The first dataset was collected from a group of 30 multiparous cows per day, whose RR was measured two times per day (i.e., between $0700 \mathrm{~h}$ and $1000 \mathrm{~h}$ and between $1100 \mathrm{~h}$ and $1400 \mathrm{~h}$; GMT $+0100 \mathrm{~h}$ ). For the second dataset, the RR of 15 primiparous and multiparous cows per day was observed hourly (i.e., from $0700 \mathrm{~h}$ to $1500 \mathrm{~h}$; GMT $+0100 \mathrm{~h}$ ). At the beginning of both time periods the cows were randomly selected from the herd and always the same cows were used per experimental day. Between the measurement days, some cows were replaced by others due to management decisions (e.g., health status, milk yield, dry period stage). Therefore, a total of 84 cows were included in the analysis over the whole time period. The cows were categorized into three lactation number groups and two DIM subgroups as follows: first and second lactation with subgroups in $\mathrm{DIM}<100$, in DIM $\geq 100$ and cows in the group of third or greater lactation without further subdivision into DIM groups. According the lactation number and DIM, there were some cows participating in both dataset collections. The time of the data collection was chosen to comprise a representative range from low to high ambient temperatures during the day period. Both datasets were collected during both time periods in 2015 and 2016, with up to three measurement days per week. This approach was used to account for variability between cows and within cows. Thirteen cows were present during both measurement periods. Cow body postures (i.e., standing vs. lying) was documented during the RR measurements. Relevant cow data (i.e., milk yield and DIM) were noted from the herd management system (Herde 5.9, DSP-Agrosoft GmbH, Ketzin, Germany).

\section{Environmental measurements}

The ambient temperature (AT) and relative humidity $(\mathrm{RH})$ of the air in the barn were recorded every 5 min with eight data loggers (EasyLog USB 2+, Lascar Electronics Inc., Whiteparish, UK) positioned $3.4 \mathrm{~m}$ above the floor at eight locations inside the building according to the methodology published by Hempel et al. (2018). Mean AT and mean RH of all loggers were calculated at each time point. The temperature-humidity index was calculated according to NRC (1971) as follows:

$$
T H I=\left(1.8 \times T^{\circ} \mathrm{C}+32\right)-(0.55-0.0055 \times R H) \times\left(1.8 \times T^{\circ} \mathrm{C}-26\right)
$$

where:

$\mathrm{T}^{\circ} \mathrm{C}$ is the dry bulb temperature (in ${ }^{\circ} \mathrm{C}$ ) and $R H$ is the relative humidity (in \%). The categories of $\mathrm{THI}$ for heat stress in dairy cattle were assigned according to Zimbelman and Collier (2011), adapted from Armstrong (1994), as follows: THI $<68$ as no stress; $68 \leq T H I<72$ as the stress threshold; $72 \leq T H I<80$ as mild stress; $80 \leq$ $T H I<90$ as moderate stress, and $T H I \geq 90$ as severe stress. 


\section{Statistical analysis}

The data from both datasets of RR collections were pooled for statistical analysis. Initially, the RR values were linked to the THI values from the start of every five-minute interval for the analysis. A regression analysis of $R R$ as a function of THI was performed separately for standing and lying cows. An exponential function with base "e" was fitted to the observed RRs. To allow comparisons with the stress levels found in the literature, THI was classified as described above in Environmental measurements. A linear mixed model with repeated measurements for each cow was used to test the influences of the environmental and cow-related factors (body postures, daily milk yield) on RR. The model assumed normally distributed residuals with homogeneous variance, and these prerequisites were checked visually after fitting the model. The lactation number category was not included in the model, because the measurements during the trial periods were not carried out with the same cow in different lactations. The fixed factors in the model were THI category (THI $<68$ no stress; $68 \leq$ THI $<72$ stress threshold; $72 \leq$ THI $<80$ mild stress; 80 $\leq$ THI $<90$ moderate stress, and THI $\geq 90$ severe stress) and body postures (standing vs. lying). The interaction between body postures and THI category was also included. The co-variables were daily milk yield and the interaction of daily milk yield with THI category. The random cow effect considered a cow-specific intercept, as well as an interaction between body postures and THI category. The model was as follows:

$$
\begin{aligned}
& Y_{i j k l}=\mu+p_{i}+t h i_{j}+(p \times t h i)_{i j}+t d_{m}+a \cdot d m y+b_{j} \cdot d m y+c o w_{k i}+p_{i k}+t h i_{j k}+ \\
& (p \times \text { thi })_{i j k}+e_{i j}
\end{aligned}
$$

where:

$Y_{i j k l}$ is the observed RR on the $k$ th cow during the $l$ th measurement in postures $\mathrm{i}$ and in temperature-humidity index category $\mathrm{j}$ on the $m$ th test-day, $\mu$ is the mean RR, $p_{i}$ is the cow's body postures, $t h i_{i j l}$ is the temperature-humidity index category, $t d_{m}$ is the fixed test day effect, $d m y$ is the daily milk yield with the regression coefficient $\alpha$ for the general slope and the regression coefficient $b_{j}$ for the interactions with the THI category, $c o w_{k l}$ is the random cow effect with $p_{i k}$ and thi $i_{j k}$ as cow-specific postures and THI category effects, and $e_{i j k l}$ is the residual.

A variance component covariance structure was used for random effects and repeated measurements. Factor influences were tested at a significance level of 0.05 . The differences between the factor levels of the significant factors were post hoc tested by t-tests in multiple pairwise comparisons. The $\mathrm{P}$-values of those multiple comparisons were adjusted by a simulation of the true $95 \%$-quantile of the contrasts, maintaining a global significance level of 0.05 . Model viability was checked by a visual examination of the residuals (homogeneity of variance and normality). All analyses were performed using SAS 9.4 (SAS Institute Inc., Cary, NC, USA). 


\section{Results}

\section{Environmental parameters}

Overall, the mean values for AT, RH, and THI during the measurements (from June 2015 to April 2016) were $17.72 \pm 8.83^{\circ} \mathrm{C}$ (mean \pm SD), $74.02 \pm 18.39 \%$, and $61.82 \pm 13.52$, respectively. Table 1 shows the monthly barn climate conditions during the experimental period of the present study.

Table 1. Barn climate characteristics during the experimental period (June 2015 to April 2016)

\begin{tabular}{|c|c|c|c|c|c|c|c|c|c|}
\hline & \multicolumn{3}{|c|}{ Temperature $\left({ }^{\circ} \mathrm{C}\right)$} & \multicolumn{3}{|c|}{ Relative humidity (\%) } & \multicolumn{3}{|c|}{$\begin{array}{l}\text { Temperature-humidity } \\
\text { index }\end{array}$} \\
\hline & Mean \pm SD & Min & Max & Mean \pm SD & Min & Max & Mean \pm SD & Min & Max \\
\hline \multicolumn{10}{|l|}{2015} \\
\hline June & $22.4 \pm 3.8$ & 14.1 & 29.4 & $55.3 \pm 12.9$ & 32.4 & 87.1 & $68.4 \pm 4.5$ & 57.5 & 76.1 \\
\hline July & $21.4 \pm 4.4$ & 13.6 & 31.3 & $63.8 \pm 14.5$ & 34.4 & 93.5 & $67.7 \pm 5.5$ & 56.6 & 79.3 \\
\hline August & $23.5 \pm 5.1$ & 16.0 & 34.5 & $70.9 \pm 17.1$ & 36.2 & 95.5 & $70.9 \pm 6.5$ & 60.7 & 85.1 \\
\hline \multicolumn{10}{|l|}{2016} \\
\hline January & $4.7 \pm 4.9$ & -8.3 & 11.9 & $94.9 \pm 5.2$ & 77.6 & 99.8 & $40.8 \pm 8.9$ & 17.8 & 53.6 \\
\hline February & $4.5 \pm 2.7$ & -0.9 & 10.2 & $92.0 \pm 8.2$ & 72.7 & 100.0 & $40.7 \pm 5.2$ & 30.6 & 51.5 \\
\hline March & $6.4 \pm 2.0$ & -0.3 & 11.1 & $91.9 \pm 7.9$ & 60.9 & 100.0 & $44.1 \pm 3.9$ & 31.8 & 53.2 \\
\hline April & $12.1 \pm 3.2$ & 5.9 & 20.5 & $76.2 \pm 11.6$ & 54.5 & 95.1 & $54.2 \pm 5.2$ & 43.5 & 67.0 \\
\hline
\end{tabular}

\section{Animal-related parameters}

The dataset of 2922 animal observations (i.e. THI $<68$ : $1536 ; 68 \leq$ THI $<72$ : $342 ; 72 \leq$ THI $<80: 784$ and $80 \leq$ THI $<90$ : 260) from a total of 84 cows with between two and nine observations per day each during the whole experimental period of 54 days was included in the model. Table 2 shows the mean RR for lying and standing cows in different THI categories including the effect on RR among THI categories. The RR differed significantly between all THI categories and body postures (lying vs. standing), except for between the postures in the $80 \leq \mathrm{THI}<90$ category. In the categories with THI values less than 80, lying cows showed higher RRs than standing cows. There were significant interactions between THI category and body postures $(\mathrm{P}<0.01)$. In both standing and lying cows the $\mathrm{RR}$ increased with increasing THI value (Table 2).

There was a significant influence of milk yield of cows on RR in different THI categories $(\mathrm{P}=0.0056)$. Figure 2 shows the regressions and confidence limits of the effect of body postures (standing vs. lying), daily milk yield of cows in $\mathrm{kg}$ produced per day and in different THI categories. The average increase in RR was $0.23 \pm 0.19$ (mean \pm standard error) per additional $\mathrm{kg}$ of milk produced beyond a $25 \mathrm{~kg}$ daily milk yield (Figure 2). Cows with a high milk yield of $60 \mathrm{~kg}$ per day tended to present higher RR (9 bpm) than cows with a low milk yield of $25 \mathrm{~kg}$ per day. 
Table 2. Least-square means of respiration rate $(\mathrm{RR}$ in $\mathrm{bpm})$ for interactions of different cow postures and temperature-humidity index (THI) categories ( $\mathrm{n}=84$ cows)

\begin{tabular}{l|l|c|c|c|c}
\hline \multirow{2}{*}{ THI category } & \multicolumn{2}{|c|}{$\begin{array}{c}\text { Respiration rate } \\
\text { Standing posture }\end{array}$} & \multicolumn{2}{c|}{$\begin{array}{c}\text { Respiration rate } \\
\text { Lying posture }\end{array}$} & \multirow{2}{*}{ P-value } \\
\cline { 2 - 5 } & mean & SEM $^{2}$ & mean & SEM $^{2}$ & \\
\hline THI $<68$ & 30.0 & 0.78 & 36.9 & 0.85 & $<0.01$ \\
$68 \leq$ THI $<72$ & 37.9 & 0.99 & 46.1 & 1.37 & $<0.01$ \\
$72 \leq$ THI $<80$ & 44.6 & 0.88 & 52.7 & 1.07 & $<0.01$ \\
$80 \leq$ THI $<90$ & 75.4 & 1.39 & 68.9 & 2.14 & 0.07 \\
P-value & $<0.01$ & & $<0.01$ & & \\
\hline
\end{tabular}

${ }^{2}$ Standard error of the mean (SEM).

Multiple custom pairwise comparison was performed $(\alpha=0.05)$.

$\mathrm{P}$-values in the last column indicate respiration rate differences according to body postures.

$\mathrm{P}$-values in the last row indicate respiration rate differences according to THI categories.

RR increased with increasing THI category $(\mathrm{P}<0.001)$ regardless of body postures. Figure 1 shows data of individual cow RR in bpm in different body postures (standing vs. lying) depending on the THI category. High variability of RR among cows was observed under identical THI conditions. The variability increased with increasing THI.

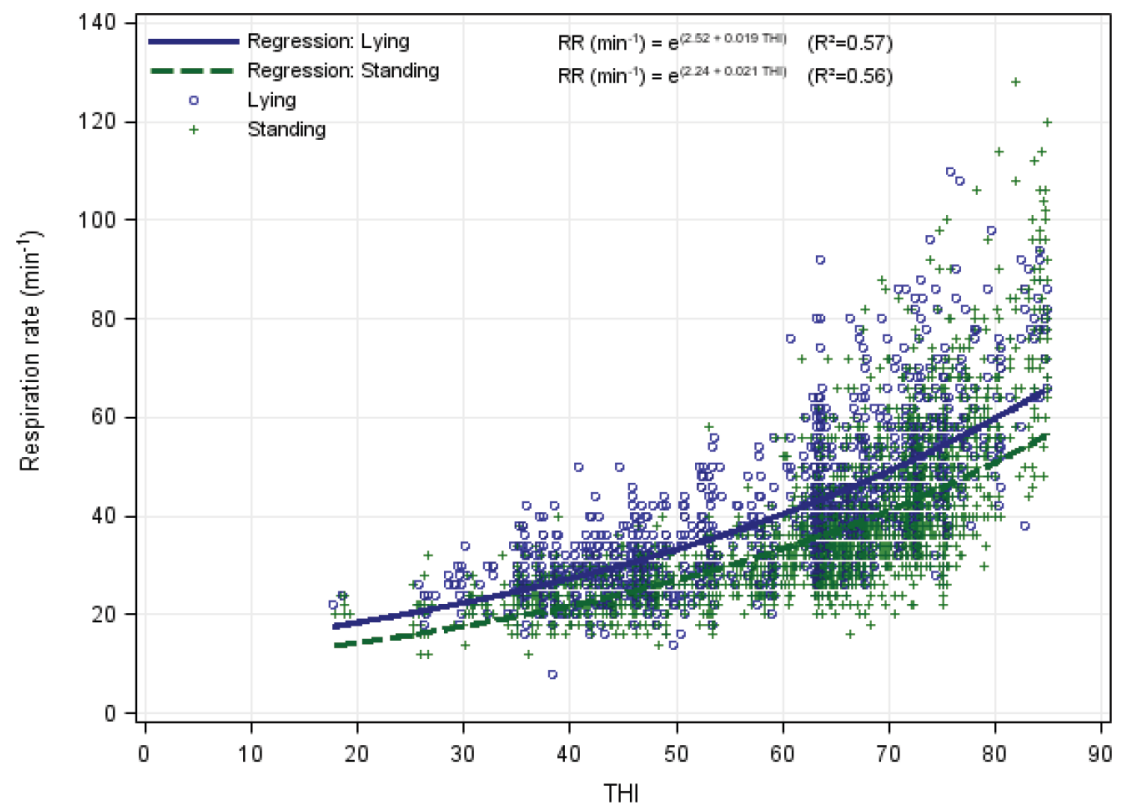

Figure 1. Individual cow respiration rate per minute with regard to body postures: standing $(+)$ and lying (०). The dotted line denotes the regression analysis for the standing posture, and the solid line denotes the regression analysis for the lying posture 


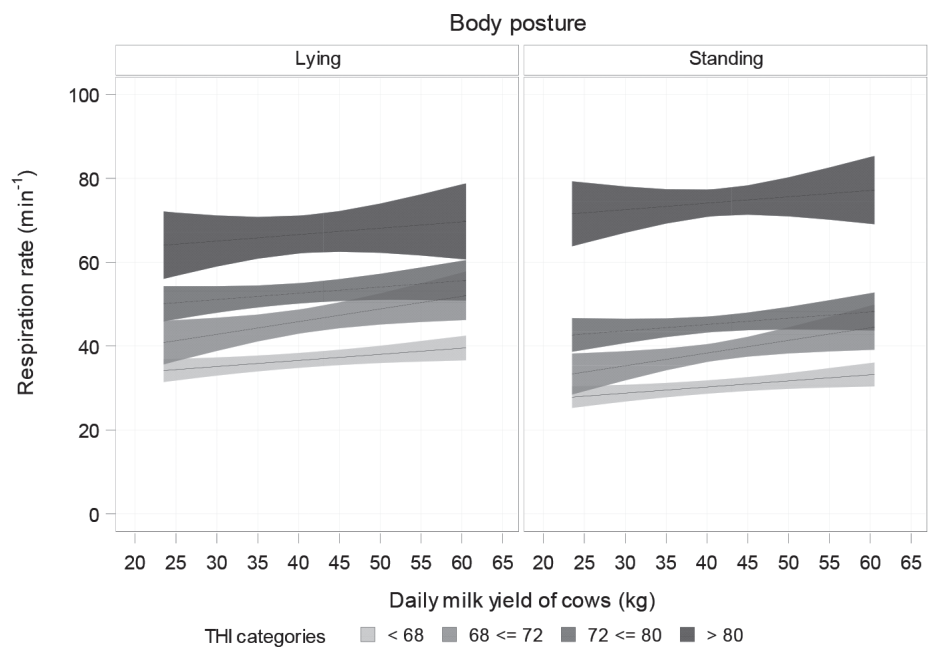

Figure 2. Respiration rate (RR) in breaths per minute (bpm) of cows in different body postures (standing vs. lying), including daily milk yield of cows and in different THI categories (THI < 68; $68 \leq \mathrm{THI}<72$; $72 \leq \mathrm{THI}<80$ and $80 \leq \mathrm{THI}<90$ ). Regressions (lines) as well as the $95 \%$ confidence limits (shaded bands) for mean RR as a function of milk yield are shown

\section{Discussion}

Effects of THI on physiological parameters such as RR have been documented before (Kabuga, 1992; Brown-Brandl et al., 2005; Chen et al., 2015) and were confirmed by our study. In the present study, the data showed a RR of $30 \pm 8.51$ (mean \pm SD) bpm for standing cows and a RR of $37 \pm 11.1 \mathrm{bpm}$ for lying cows at THI below 68. Jackson and Cockcroft (2008) reported that the physiological RR of cows ranges from 15 to $36 \mathrm{bpm}$, but like in other previous studies no differentiation was made between standing and lying posture. However, the results of our study differ from results of Garner et al. (2017), who considered THI between 55 and 61 as thermoneutral conditions for high-yielding dairy cows (mean daily milk yield: $23 \mathrm{~kg} / \mathrm{cow}$ ) and observed RRs between 43 and $56 \mathrm{bpm}$. We supposed that the RR do not differ solely due to the THI conditions to which the cows were subjected in this study. Various factors such as body postures and milk yield may influence the respiration rate of cows. Some works confirm that the individual cow factors can influence the physiological parameters and susceptibility of dairy cows to heat stress (Gaughan et al., 2000; Berman, 2005), however, those cow factors were not included in the analysis of Jackson and Cockcroft (2008) and Garner et al. (2017). Further studies (using the same THI formula) in which THI $<62$ (recently freshened cows; Spiers et al., 2004), and THI < 75 (non-lactating multiparous cows; Ferrazza et al., 2017) were defined as no heat stress conditions observed different RR results as $59 \mathrm{bpm}$ and $39 \mathrm{bpm}$, respectively. Therefore, there seemed to be an effect of lactation period and milk yield on the RR of cows, even under thermoneutral conditions. 
The mean RR in the $68 \leq \mathrm{THI}<72$ category increased by $21.9 \%$ (9 bpm units) compared to that in cows under THI $<68$ conditions. The THI of 68 is considered as the heat stress threshold of dairy cows (Bryant et al., 2007; Zimbelman and Collier, 2011). When THI increased to $\geq 80$ in our study, RR increased by $39 \mathrm{bpm}$ over those observed under THI $<68$ conditions. Influences of heat stress on RR were also observed in a study with eight steers carried out by Brown-Brandl et al. (2005), in which RR differed by $15 \mathrm{bpm}$ between baseline and heat stress levels. The more significant increase in our study may be explained by the use of high-yielding dairy cows instead of steers. In another study conducted with eight lactating cows (producing $37.4 \mathrm{~kg}$ of milk per day), RR increased from $60 \mathrm{bpm}(\mathrm{THI}=69)$ to $87 \mathrm{bpm}$ (THI = 80; Ominski et al., 2002).

Based on THI conditions of $68 \leq$ THI $<72$, an average bpm of $42 \pm 11.9$ (mean $\pm \mathrm{SD}$ ) was observed in our study. This RR value is comparable to the value (37 bpm) reported in a previous study but with a mean THI of 74 (Ferrazza et al., 2017). Previous studies described large variation among cows under similar environmental conditions. The RR varies among different studies in THI conditions $\leq 73$, with reported RR values of $54 \pm 2.4$ (mean \pm SEM) bpm (Kendall et al., 2007), $60 \pm 1.9$ bpm (Ominski et al., 2002) and 67士3.7 bpm (Brown-Brandl et al., 2005; Costa et al., $2015 \mathrm{~b}$ ). Our study confirms a high variability in RR (28 to $38 \mathrm{bpm}$ ) among cows under conditions of THI $<68$. In dairy cows under an average THI condition of 74, Ferrazza et al. (2017) observed a RR variation between 26 and $61 \mathrm{bpm}$. It is plausible to assume that the observed variability in $\mathrm{RR}$ is indicative of differences in heat stress adaption among cows (Kendall et al., 2007). Hence, the cows are not adapted to hot conditions, the cows tend to react individually and might reduce the milk production and animal welfare (Herbut and Angrecka, 2013).

Measurement locations also played a role in our study: although our environmental data were collected by eight loggers positioned in different locations inside the building at $3.4 \mathrm{~m}$ height, THI varied by up to \pm 2 units among locations within the barn, which is in agreement with a previous study (Hempel et al., 2018). Microclimates can be observed in different areas within a given barn (Herbut et al., 2015). Our study had a distinctively greater spatial resolution of THI measurements due to the higher number of loggers inside the barn, a real environmental situation could not be observed. However, Hempel et al. (2018) affirmed that positioning of the loggers between 3.4 and $4 \mathrm{~m}$ height is suitable for a representative presentation of the barn environment because below this range (i.e., in animal occupied zone), deviations in relative humidity of the environmental data can be observed. In addition, in most studies investigating heat stress in the field, ambient temperature and humidity measurements were obtained either from nearby weather stations or on site at one or two locations (Schueller et al., 2014).

Several factors must be considered when investigating the relationship between THI and RR. Previous studies reported influences of the body postures on the wind convection of cows. Lying cows show a decrease of $42 \%$ of the body surface area in heat dissipation compared to standing cows (Frazzi et al., 2000; Wang et al., 2018). To our knowledge, this is the first study reporting that body postures influenced RR under different THI conditions. The influences of individual cow factors such as milk 
yield, body condition and behavior on the physiological reactions of cows has been described in previous studies (Tucker et al., 2008; Schutz et al., 2010; Gauly et al., 2013). However, these previous studies did not focus on the influences of cow-related factors such as body postures on the RR of heat-stressed dairy cows. Our results show that the RR values of lying cows were significantly greater than those of standing cows under the same THI conditions. Cows in a lying posture showed $7 \pm 0.51$, $8 \pm 1.32$, and $8 \pm 0.88$ (mean \pm SEM) bpm more than did standing cows under no stress, at the stress threshold, and in mild heat stress, respectively. The importance of body postures suggests that lying cows may develop heat stress earlier and at a lower temperature threshold than do standing cows (Berman, 2005). The straw bedding used in the present study might increase the heat load in lying cows; hence standing cows are more exposed to airflow and increase the wind convection (Wang et al., 2018). In THI conditions $>74$, cows avoided to rest on the straw bedding during the day (Angrecka and Herbut, 2017). In addition, some authors have suggested that the body contours of cows change when they lie down, causing the rumen to compress the diaphragm and thereby reducing lung capacity and respiration effectiveness (Santos and Overton, 2001; Tucker et al., 2008; Reece and Rowe, 2017). This phenomenon was observed in our results even under low or absent heat stress conditions.

In conditions of THI $\geq 80$, the cows showed no significant differences in RR due to body postures. We observed that when cows were already under high heat stress conditions, body postures was not a load factor for RR response, with an average RR of $72 \mathrm{bpm}$. The prevalence of RRs of approximately 70 to $80 \mathrm{bpm}$ suggests that these RRs provide heat stress relief for the cows (Stevens, 1981; Berman, 2005). High RR values are associated with long periods of standing to release heat efficiently by wind convection and avoid the breathing discomfort of lying down (Frazzi et al., 2000; Berman, 2005; Wang et al., 2018). Soriani et al. (2013) observed a negative relationship between rumination time and respiration rate in lactating cows under heat stress conditions, although rumination time in the lying down postures enhances production as well as cow comfort (Acatincăi et al., 2010; Herbut and Angrecka, 2018 a).

Our results demonstrated significant differences in RR in bpm with respect to daily milk yield in addition to body postures. The RR increased with increasing daily milk yield. The respiration rates of cows with a milk yield of $60 \mathrm{~kg}$ per day were $9 \mathrm{bpm}$ higher than those of cows with a $25 \mathrm{~kg}$ milk yield per day. High-yielding cows are likely to be more affected by THI increases, because of the metabolizable energy used for milk production (Hahn, 1999; Kadzere et al., 2002), where high-producing cows have significantly more heat to dissipate than low-producing cows (West, 2003; Herbut et al., 2015). Published studies considering RR reactions in relation to milk yield in dairy cows are not common. In a recent study with lactating cows conducted by Santos et al. (2017), the authors did not observe changes in RR with regard to milk yield level, although, the cows included in their study had an average milk yield of $20 \mathrm{~kg}$ in comparison with $41 \mathrm{~kg}$ in the present study. Furthermore, Dikmen and Hansen (2009), who conducted a study about rectal temperature in lactating cows, did not identify a relationship between milk yield and rectal temperature.

In conclusion, the present study provides quantified evidence that the respiration rate (RR) in dairy cows increases with THI. The effects of body postures and milk 
yield on RR under different THI conditions were determined. Cows in a lying posture showed higher RRs than standing cows in "no stress" (THI < 68), "stress threshold" $(68 \leq \mathrm{THI}<72)$ and "mild stress" $(72 \leq \mathrm{THI}<80)$ THI categories. The RRs in high-producing cows ( $>25 \mathrm{~kg}$ milk per day) increased for each additional kilogram of milk produced. The consideration of cow-related factors (body postures and milk yield) can reduce the uncertainty in the correlations between RR data and heat stress assessments. Further research is necessary to verify whether body postures and milk yield influence the RR of lactating dairy cows under hot climate conditions and under different management strategies for heat stress relief (e.g., cooling). Our results support the use of RR as an early heat stress indicator. Determining the differences between cows within the same THI category with greater precision will require the development of an RR sensor or a corresponding learning algorithm for individual animals.

\section{Acknowledgments}

The authors gratefully acknowledge the staff of the Department of Engineering for Livestock Management at the ATB Institute and, in particular, Theresa MüschnerSiemens, Julia Heinicke, Annemarie Englisch, Sabrina Hempel and Woutine Pauw, and the staff of the dairy farm at the Agricultural Research and Education Center for Animal Breeding and Husbandry "Gross Kreutz" in Brandenburg where we carried out the experiments.

This project was funded by the "optimized animal-specific barn climatization facing temperature rise and increased climate variability" (OptiBarn) project of the FACCE ERA-NET Plus Initiative "Climate Smart Agriculture" in Brussels and by the "Projektträger Bundesanstalt für Landwirtschaft and Ernährung" (PTBLE - funding code: 315-06.01- 2814ERA02C) in Bonn and scholarship from the Coordination for Improvement of Higher Education Personnel - CAPES (Brazil).

\section{References}

A c a tincăi S., Gavojdian D., Stanciu G., Cziszter L.T., Tripon I., B a u l S. (2010). Study regarding rumination behavior in cattle - position adopted by cows during rumination process. Sci. Pap. Anim. Sci. Biotechnol., 43: 199-202.

Aharoni Y., Brosh A., Harari Y. (2005). Night feeding for high-yielding dairy cows in hot weather: effects on intake, milk yield and energy expenditure. Livest. Prod. Sci., 92: 207-219.

A n g r e c k a S., H e r b u t P. (2017). Eligibility of lying boxes at different THI levels in a freestall barn. Ann. Anim. Sci., 17: 257-269.

A r m s tr o n g D.V. (1994). Heat stress interaction with shade and cooling. J. Dairy Sci., 77: 2044-2050.

B e r m a n A. (2003). Effects of body surface area estimates on predicted energy requirements and heat stress. J. Dairy Sci., 86: 3605-3610.

B erman A. (2005). Estimates of heat stress relief needs for Holstein dairy cows. J. Anim. Sci., 83: $1377-1384$.

B rown-Brand 1 T.M., Eigen berg R.A., Ni en aber J.A., H ahn G.L. (2005). Dynamic response indicators of heat stress in shaded and non-shaded feedlot cattle, Part 1: Analyses of indicators. Biosys. Eng., 90: 451-462. 
Bryant J.R., Lopez-Villalobos N., Pryce J.E., Holmes C.W., Johns on D.L., Garrick D.J. (2007). Environmental sensitivity in New Zealand dairy cattle. J. Dairy Sci., 90: 1538-1547.

Chen J.M., S chutz K.E., Tu c ker C.B. (2015). Cooling cows efficiently with sprinklers: Physiological responses to water spray. J. Dairy Sci., 98: 6925-6938.

Costa A.N., F e ito s a J.V., J un ior P.A., d e S o uza P.T., d e Araujo A.A. (2015 a). Hormonal profiles, physiological parameters, and productive and reproductive performances of Girolando cows in the state of Ceara-Brazil. Int. J. Biometeorol., 59: 231-236.

Costa A.N., Feitosa J.V., Montezuma P.A. Jr., de Souza P.T., de Araujo A.A. (2015 b). Rectal temperatures, respiratory rates, production, and reproduction performances of crossbred Girolando cows under heat stress in northeastern Brazil. Int. J. Biometeorol., 59: 1647-1653.

D i k m e n S., H a n s e n P.J. (2009). Is the temperature-humidity index the best indicator of heat stress in lactating dairy cows in a subtropical environment? J. Dairy Sci., 92: 109-116.

F errazza R.D., G arci a H.D.M., A ri stizabal V.H.V., Nogue ir a C.D., Veris s i mo C.J., S artori J.R., S artori R., Ferre ir J.C.P. (2017). Thermoregulatory responses of Holstein cows exposed to experimentally induced heat stress. J. Therm. Biol., 66: 68-80.

Frazzi E., Calamari L., Calegari F., Stefanini L. (2000). Behavior of dairy cows in response to different barn cooling systems. T. Asae, 43: 387-394.

G a rn er J.B., D o u g l a s M., Willi a m s S.R.O., Wa le s W.J., Mare t t L.C., D i G i a c o mo K., L e u r y B.J., H a y e s B.J. (2017). Responses of dairy cows to short-term heat stress in controlledclimate chambers. Anim. Prod. Sci., 57: 1233-1241.

G a u g h a n J.B., H o $1 \mathrm{t}$ S.M., H a h n G.L., M a d e r T.L., E i g e n b e rg R. (2000). Respiration rateis it a good measure of heat stress in cattle? Asian Austral. J. Anim., 13: 329-332.

Gauly M., Bollwein H., Breves G., Brugemann K., Danicke S., Das G., Demeler J., Hansen H., Is selstein J., Konig S., Loholter M., Martinsohn M., Mey e r U., P ot th off M., S a n ker C., S chroder B., Wrage N., M e ib a u m B., von S a ms on-Himmels tjerna G., Stinshoff H., Wrenzycki C. (2013). Future consequences and challenges for dairy cow production systems arising from climate change in Central Europe a review. Animal, 7: 843-859.

H a hn G.L. (1999). Dynamic responses of cattle to thermal heat loads. J. Anim. Sci., 77: 10-20.

He in i cke J., H offm a n n G., A m m on C., A m o n B., A mon T. (2018). Effects of the daily heat load duration exceeding determined heat load thresholds on activity traits of lactating dairy cows. J. Therm. Biol., 77: 67-74.

Hempel S., König M., Menz C., Janke D., Amon B., Banhazi T.M., Estellés F., A m o n T. (2018). Uncertainty in the measurement of indoor temperature and humidity in naturally ventilated dairy buildings as influenced by measurement technique and data variability. Biosyst. Eng., 166: 58-75.

H e r b u t P., A n g re c k a S. (2013). Forecasting heat stress in dairy cattle in selected barn zones with the help of THI and THIadj indexes. Ann. Anim. Sci., 13: 837-848.

H e r b u t P., A n g r e c k a S. (2018 a). Relationship between THI level and dairy cows' behaviour during summer period. Ita. J. Ani. Sci., 17: 226-233.

H e r b u t P., A n g r e c k a S. (2018 b). The effect of heat stress on time spent lying by cows in a housing system. Ann. Anim. Sci., 18: 825-833.

Herbut P., Angre cka S., N a w a l any G., A d a m c z y k K. (2015). Spatial and temporal distribution of temperature, relative humidity and air velocity in a parallel milking parlour during summer period. Ann. Anim. Sci., 15: 517-526.

Jacks on P., Cockcroft P. (2008). Clinical Examination of Farm Animals. Wiley-Blackwell, $320 \mathrm{pp}$.

Kabuga J.D. (1992). The influence of thermal conditions on rectal temperature, respiration rate and pulse rate of lactating Holstein-Friesian cows in the humid tropics. Int. J. Biometeorol., 36: $146-150$.

Ka d z e re C.T., Murphy M.R., S i l a n i k o ve N., M a ltz E. (2002). Heat stress in lactating dairy cows: a review. Livest. Prod. Sci., 77: 59-91.

Kendall P.E., Verkerk G.A., Webster J.R., Tucker C.B. (2007). Sprinklers and shade cool cows and reduce insect-avoidance behavior in pasture-based dairy systems. J. Dairy Sci., 90 : 3671-3680. 
L e gates J.E., F arthing B.R., C a s ady R.B., B arrada M.S. (1991). Body temperature and respiratory rate of lactating dairy cattle under field and chamber conditions. J. Dairy Sci., 74: 24912500 .

Moallem U., Altmark G., Lehrer H., Arieli A. (2010). Performance of high-yielding dairy cows supplemented with fat or concentrate under hot and humid climates. J. Dairy Sci., 93: 3192-3202.

NRC (1971). A guide to environmental research on animals. Nat. Acad. Sci., Washington, DC.

O minski K.H., Kennedy A.D., Wittenberg K.M., N i a S.A.M. (2002). Physiological and production responses to feeding schedule in lactating dairy cows exposed to short-term, moderate heat stress. J. Dairy Sci., 85: 730-737.

Ree ce W.O., R ow e E.W. (2017). Functional anatomy and physiology of domestic animals. New Jersey, USA, Wiley-Blackwell, 5th ed., $576 \mathrm{pp}$.

R o s e n berger G. (1990). Clinical examination of cattle (Die klinische Untersuchung des Rindes). Berlin, Germany, Parey, 3rd ed., 718 pp.

S a n t o s J.E.P., O v e r t o n M.W. (2001). Diet, feeding practices and housing can reduce lameness in dairy cattle. Proc. Intermountain Nutrition Conference, Utah, USA, pp. 145-161.

Santos S.G., Saraiva E.P., Pimenta Filho E.C., Gonzaga Neto S., Fonsêca V.F., P in heiro A.D., A $1 \mathrm{~m}$ e i d a M.E., d e A m orim M.L. (2017). The use of simple physiological and environmental measures to estimate the latent heat transfer in crossbred Holstein cows. Int. J. Biometeorol., 61: 217-225.

S chueller L.K., B u r fe ind O., H e u w i e s e r W. (2014). Impact of heat stress on conception rate of dairy cows in the moderate climate considering different temperature-humidity index thresholds, periods relative to breeding, and heat load indices. Theriogenology, 81: 1050-1057.

S chutz K.E., R o gers A.R., P o u lou in Y.A., Cox N.R., Tucker C.B. (2010). The amount of shade influences the behavior and physiology of dairy cattle. J. Dairy Sci., 93: 125-133.

S or i a ni N., Panella G., C a la mari L. (2013). Rumination time during the summer season and its relationships with metabolic conditions and milk production. J. Dairy Sci., 96: 5082-5094.

S p i e r s D.E., S p a in J.N., S a m p s o n J.D., R h o a d s R.P. (2004). Use of physiological parameters to predict milk yield and feed intake in heat-stressed dairy cows. J. Therm. Biol., 29: 759-764.

S t e ve n s D.G. (1981). A model of respiratory vapor loss in Holstein dairy cattle. Trans. ASAE, 24: $151-158$.

Tu c k e r C.B., R o g e r s A.R., S c hut z K.E. (2008). Effect of solar radiation on dairy cattle behaviour, use of shade and body temperature in a pasture-based system. Appl. Anim. Behav. Sci., 109: $141-154$.

Wang X.S., Zhang G.Q., Cho i C.Y. (2018). Effect of airflow speed and direction on convective heat transfer of standing and reclining cows. Biosyst. Eng., 167: 87-98.

We s t J.W. (2003). Effects of heat-stress on production in dairy cattle. J. Dairy Sci., 86: 2131-2144.

Z i m be $1 \mathrm{~m}$ a n R.B., C o 11 i e r R.J. (2011). Feeding strategies for high-producing dairy cows during periods of elevated heat and humidity. Proc. Tri-State Dairy Nutrition Conference, Fort Wayne, IN, pp. 111-125.

Received: 17 IX 2018

Accepted: 24 I 2019 